\title{
Piezoelectric nanogenerator for bio-mechanical strain measurement
}

\author{
Zafar Javed ${ }^{1}$, Lybah Rafiq², Muhammad Anwaar Nazeer², Saqib Siddiqui ${ }^{3}$, \\ Muhammad Babar Ramzan², Muhammad Qamar Khan ${ }^{4}$ \\ and Muhammad Salman Naeem ${ }^{* 1}$
}

\section{Full Research Paper}

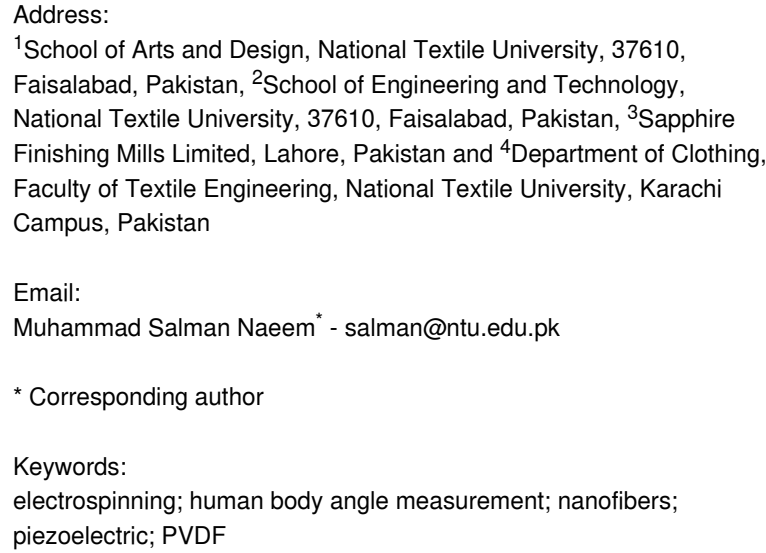

${ }^{1}$ School of Arts and Design, National Textile University, 37610, Faisalabad, Pakistan, ${ }^{2}$ School of Engineering and Technology, National Textile University, 37610, Faisalabad, Pakistan, ${ }^{3}$ Sapphire Finishing Mills Limited, Lahore, Pakistan and ${ }^{4}$ Department of Clothing, Faculty of Textile Engineering, National Textile University, Karachi Campus, Pakistan

Email:

Muhammad Salman Naeem - salman@ntu.edu.pk

* Corresponding autho

Keywords:

electrospinning; human body angle measurement; nanofibers; piezoelectric; PVDF

Beilstein J. Nanotechnol. 2022, 13, 192-200. https://doi.org/10.3762/bjnano.13.14

Received: 08 October 2021

Accepted: 25 January 2022

Published: 07 February 2022

This article is part of the thematic issue "Nanomaterial-based sensors for water remediation, healthcare and food monitoring applications".

Guest Editor: A. A. Oladipo

(C) 2022 Javed et al.; licensee Beilstein-Institut. License and terms: see end of document.

\begin{abstract}
Piezoelectric materials have attracted more attention than other materials in the field of textiles. Piezoelectric materials offer advantages as transducers, sensors, and energy-harvesting devices. Commonly, ceramics and quartz are used in such applications. However, polymeric piezoelectric materials have the advantage that they can be converted into any shape and size. In smart textiles, polyvinylidene fluoride (PVDF) and other piezoelectric polymers are used in the form of fibers, filaments, and composites. In this research, PVDF nanofibers were developed and integrated onto a knitted fabric to fabricate a piezoelectric device for human body angle monitoring. Scanning electron microscopy and X-ray diffraction analyses were used to study the morphology and to confirm the beta phase in fibers. The results reveal that the nanofibers made from solutions with high concentration were smooth and defectfree, compared to the fibers obtained from solutions with low concentration, and possess high crystallinity as well. Under high dynamic strain more output voltage is generated than under low dynamic strain. The maximum current density shown by the device is $172.5 \mathrm{nA} / \mathrm{cm}^{2}$. The developed piezoelectric nanofiber sensor was then integrated into a knitted fabric through stitching to be used for angle measurement. With increasing bending angle, the output voltage increased. The promising results show that the textilebased piezoelectric sensor developed in this study has a great potential to be used as an angle measuring wearable device for the human body due to its high current density output and flexibility.
\end{abstract}




\section{Introduction}

Smart textiles are normally elevated to value-added textile products with improved properties and characteristics [1]. They exhibit properties of a textile with some added characteristics. Smart textiles are obtaining by combining conventional textile techniques, such as knitting or weaving, with different technologies of electronics [2]. The world is moving towards intelligent or smart textiles. In 2012, the size of the smart textile market was almost $\$ 289.5$ million and surged to $\$ 1,500$ million in 2020. The integration of electronically active fibers or yarns in textile substrates is the basis of smart textiles [3]. Textile-based sensors and electrodes are composed of conductive fibers, threads, or fabrics [4]. Their use for physiological and medical examination has been rising rapidly in the last couple of years. Textile-based sensors, being flexible, are easy to fit in a garment and create no barrier to the wearer. Nowadays, wearable sensors based on conductive threads and conductive polymers are capable of measuring vital signs of the human body [4,5]. Tognetti et al. [6] designed and developed a resistive strain sensors for movement analysis. They integrated an electrically conductive elastomer into a fabric, which was then able to detect the posture and the movement of the human body. Retrieved data from these strain sensors were compared with conventional motion tracking systems. The results show promising performance for body posture classification and reconstruction. Similarly, for measuring human body angles, piezoresistive sensors were developed and characterized under bending and stretching regarding the application as strain sensors [7] Knitted piezoresistive fabrics were used to develop sensors that were a wearable type of a goniometer. These sensors were then tested under static and dynamic conditions. For another application, researchers designed and developed a purely textile-based capacitive pressure sensor to be integrated and embedded into the garments to monitor and measure human body pressure. These sensors were beneficial for pressure sore prevention, rehabilitation, and the detection of movement during activities. Further, these sensors were comfortable and bendable and were applied onto the upper portion of an arm to detect the deflection of the forearm during muscle bending [8]. Park et al. [9] developed a self-powered piezoelectric sensor for monitoring the pulse rate in real time. A pressure sensor was attached to the epidermis for monitoring pulse and assessing personal health status. Traditional sensors for pulse monitoring can detect biosignals of the human body but they have the limitation of power supply, which will restrict the operation of the wearable devices for medical purposes. Hence, piezoelectric sensors were used for monitoring bio-signals of the human body without limitation of power supply. Moreover, Lorussi and co-workers developed a smart textile garment by embedding a strain sensor into an ordinary garment. For the piezoelectric effect, the conductive blend was applied onto the fabric, which resulted in a change in resistance under strain. This phenomenon was used in gloves, car seats, and leotards for determining body posture, shape, and gesture. They primarily focused on studying a leg pad that was able to perceive the knee movement and posture [10]. Piezoelectric sensors have a wide range of applications including sidewalks or crosswalks that collect energy from vibrations, which can be store in batteries [11]. Moreover, piezoelectric sensors can be used at workplaces and gyms to collect energy from machine vibrations [12]. These sensors are embedded under the shoes so that the pressure exerted during walking or running can be converted into energy and can be used for different applications. Piezoelectric sensors can also be used under mats and floors so the pressure due to footsteps can be utilized as a source to generate energy [13]. Besides these, piezoelectric sensors can also be used for sensing human body motion and monitoring physical health parameters, such as electrocardiograms [14-19]. Polyvinylidene fluoride (PVDF), having a semicrystalline structure, is generally synthesized through polymerization of vinylidene difluoride [20]. It generally has four crystalline phases, namely $\alpha, \beta, \varepsilon$, and $\gamma$. Among them, the beta phase possesses the highest dipole movements, while the other phases are usually non-polar as their structural packing is antiparallel [21]. Usually, PVDF is non-reactive towards acids and bases. It was discovered in 1969 that PVDF can produce electrical signals. Thus, it can be used in various applications of energy harvesting, in various forms such as fibers, films, monofilaments, and powder. This material is trending in textile-based research where different researchers are working to manufacture smart textiles to generate energy [22,23]. Nanofibers have many technical applications such as in air and liquid filtration [24,25], tissue engineering [26,27], drug delivery [28], wound dressings [29], sound adsorption [30], cosmetics [31], and sensor devices [32-34]. In filtration processes, electrospun nanofibers can be employed for removing volatile organic compounds (VOCs) from the atmosphere. To protect people from bacteria, viruses, smog, and dust, nanofibers are utilized in medical face masks. These masks will not allow the particles to be inhaled because of the small pore size of the nanofibrous scaffold, while oxygen molecules are small enough to pass through these pores. Nanofibers are also used in other medical applications, for instance, for developing artificial organs and blood vessels, and in gene and drug delivery [35]. Monitoring joint angles through wearable systems enables human posture and gesture to be reconstructed as a support for physical rehabilitation both in clinics and at the patients' home [36]. To date, wearable sensors used for monitoring body movements in the market are battery-based. The battery needs to be worn all the time. Also, it needs to be charged or replaced, which makes its application impractical. In this work, we present a proof of concept for using a nanofi- 
brous-based piezoelectric sensor composed of PVDF, which is capable of monitoring body angles. This sensor will be able to replace the battery being used in commonly available products and is more breathable, lightweight, and flexible. The developed sensor has been characterized through advanced techniques. The current density has been calculated and compared with the current state of the art. To the best of our knowledge, the PVDF-based nanofibrous device developed in this study is superior to previously reported ones.

\section{Experimental Materials}

Polyvinylidene fluoride (PVDF) obtained from Alfa Aesar was used as a piezoelectric material. Dimethylformamide (DMF) and acetone from Sigma-Aldrich were used as solvents without any further purification. A conductive tape was used to make electrodes. Knitted fabric was used for the integration of the nanofibrous mesh for human body angle measurement.

\section{Fabrication of the nanofibrous mesh and its characterization}

PVDF solutions with varying concentrations $(12,14$, and 16 wt $\%)$ were prepared in an acetone/DMF mixture (1:2.3 by volume). PVDF was dissolved in the acetone/DMF mixture at $120{ }^{\circ} \mathrm{C}$ in a sealed container under stirring for $4 \mathrm{~h}$ followed by incubating the solutions at room temperature for $24 \mathrm{~h}$ before electrospinning. A conventional electrospinning process was used to create the piezoelectric electrospun nanofibers. The polymeric solution was pumped from a metallic syringe needle of $0.4 \mathrm{~mm}$ inner diameter at a flow rate of $3.5 \mathrm{~mL} / \mathrm{h}$. The fibers were collected on a stationary collector placed at a working distance of $15 \mathrm{~cm}$. A constant voltage of $15 \mathrm{kV}$ was used for all the experiments. The nanofibrous meshs were first dried at room temperature in the fume hood for $24 \mathrm{~h}$ followed by drying in a vacuum oven until constant weight to ensure the complete evaporation of the solvents. PVDF nanofibers were characterized through scanning electron microscopy (SEM) and X-ray diffraction (XRD) to determine morphology and crystalline structure, respectively.

\section{Sensor development, its embedding, and testing}

The prepared PVDF nanofibrous mesh was folded into a square shape $\left(4 \mathrm{~cm}^{2}\right)$ with $2 \mathrm{~mm}$ thickness for sensor development. Subsequently, conductive tape was attached to both sides of the film in a way that it covered the maximum area of the sheet (Figure 1).

The developed piezoelectric sensor was tested in knee angle measurements using a digital oscilloscope. The sensor was exposed to low and high dynamic strains with varying frequencies to examine their effect on the output voltage. Then the developed sensor was integrated and stitched on a knitted fabric to check the effect of the bending angle on the output voltage.

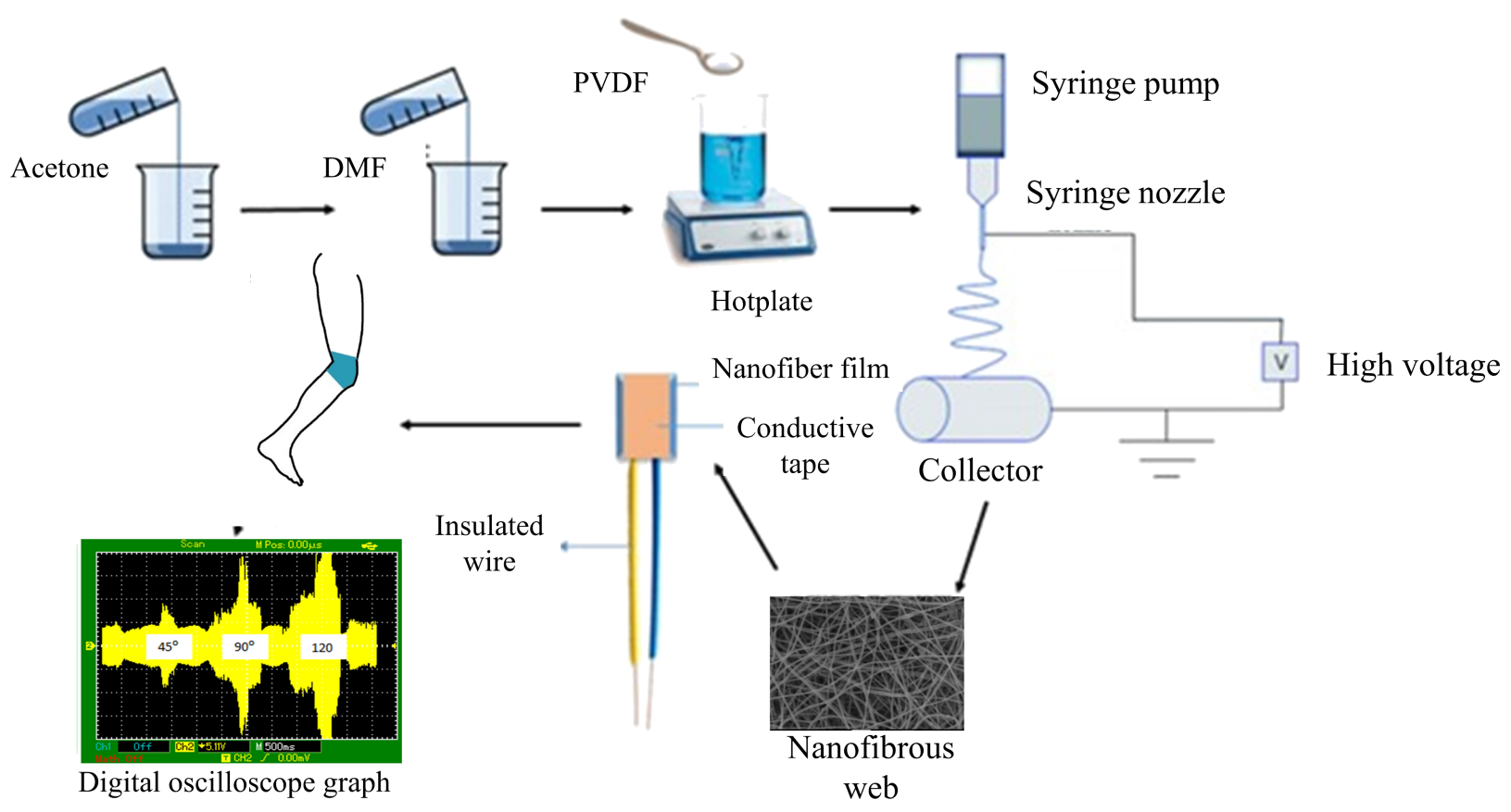

Figure 1: Illustration representing the scheme for sensor development. 
Staple spun polyester thread was used to stitch the sensor onto the knitted fabric by using a lockstitch machine. The sensor was worn on the knee and the bending angle of the knee was changed from $0^{\circ}$ to $45^{\circ}, 90^{\circ}$, and $120^{\circ}$ to check the piezoelectric output with a digital oscilloscope.

\section{Results and Discussion SEM analysis}

SEM was used to study the diameter and morphology of PVDF nanofibers developed through three different PVDF solutions $(12,14$, and $16 \mathrm{wt} \%)$. The secondary electron images, taken at $10,000 \times$ and $40,000 \times$, magnifications of prepared PVDF electrospun films from a $12 \mathrm{wt} \%$ polymer solution are shown in Figure $2 \mathrm{~A}$. The images show that the nanofibers have a more bead-on-string-like structure than the nanofibers obtained from 14 wt \% solution (Figure 2B) due to incomplete solvent evaporation. The optimum polymer solution concentration is essential to obtain defect-free smooth fibers [14,37]. The nanofibers obtained from $16 \mathrm{wt} \%$ solution were smooth and presented a bead-free morphology (Figure 2C). Therefore, these fibers were selected for developing the piezoelectric sensor. The average diameter of the fibers obtained from different solutions is provided in Figure 2D.
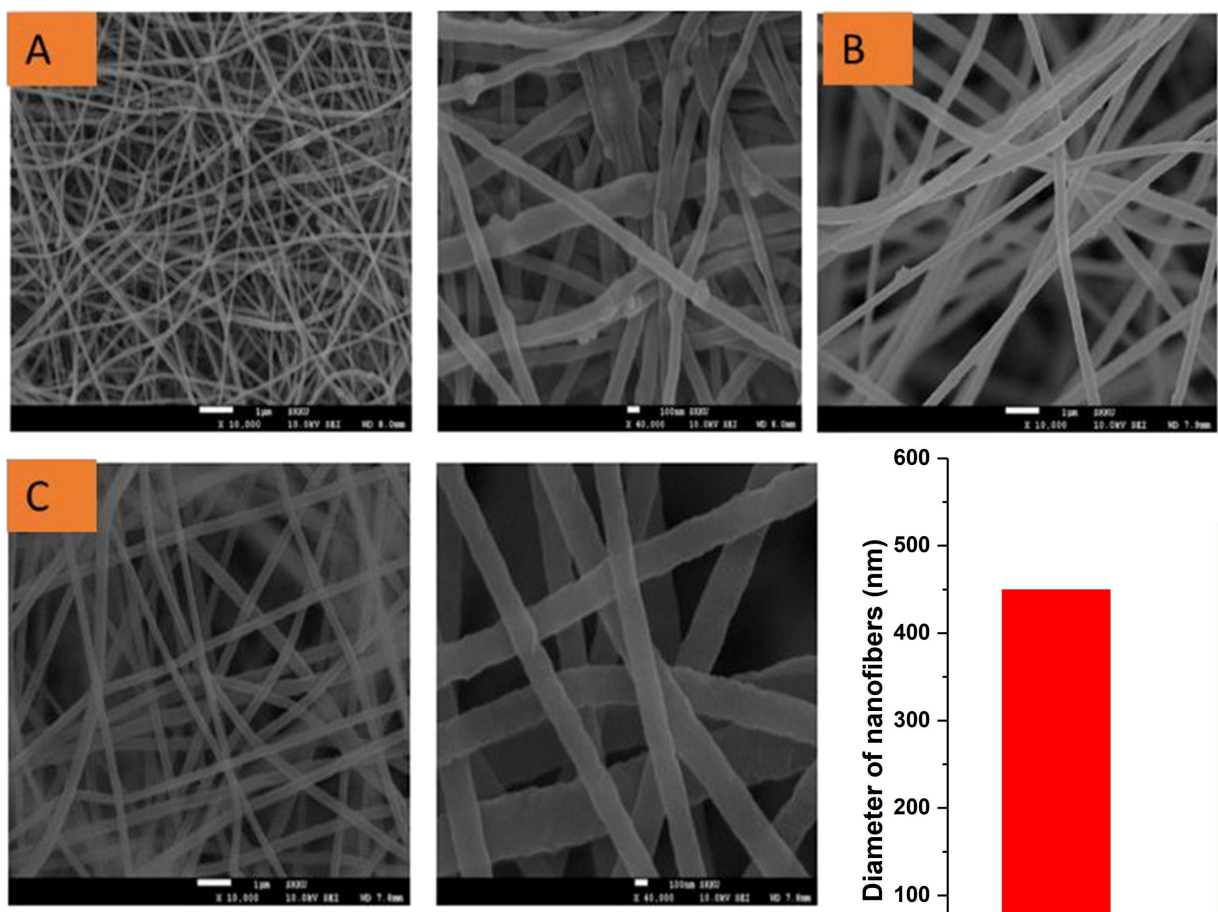

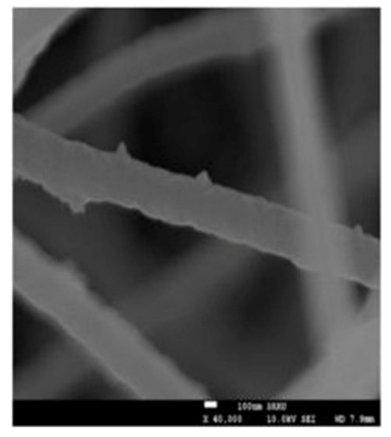

\section{XRD analysis}

PVDF exhibits four crystalline structures: $\alpha, \beta, \gamma$, and $\delta$ [38]. Normally, all phases of PVDF show almost similar peaks with the exception of unique peaks that are used to identify the crystalline structure. X-ray diffractograms were used to analyze the crystalline structure [39] of prepared PVDF nanofibrous meshs obtained from different solutions to identify the beta phase in the fibers, which is primarily accountable for piezoelectric characteristics. PVDF showed its strongest peak near $\theta=20^{\circ}$. The alpha phase has a peak around $18^{\circ}$ [40], the $\gamma$ phase has its intense peak at $19.2^{\circ}$ [41], while the beta phase exhibits peaks between 20.04 and $22.03^{\circ}$ (Figure 3).

It can be seen that the beta phase is dominant in the fibers obtained from the $16 \mathrm{wt} \%$ solution compared to the solutions of 12 and $14 \mathrm{wt} \%$. The crystallinity was calculated from the XRD diffractograms and came out to be $52.3 \%, 54.6 \%$, and $57.7 \%$ for the fibers made from 12,14 , and $16 \mathrm{wt} \%$ solutions, respectively. This phenomenon can be correlated with the high concentration of polymer solution. During evaporation of the solvent, polymer chains are more likely to form crystalline structures because they are closer together than in the solutions with lower concentration Also, when the polymer

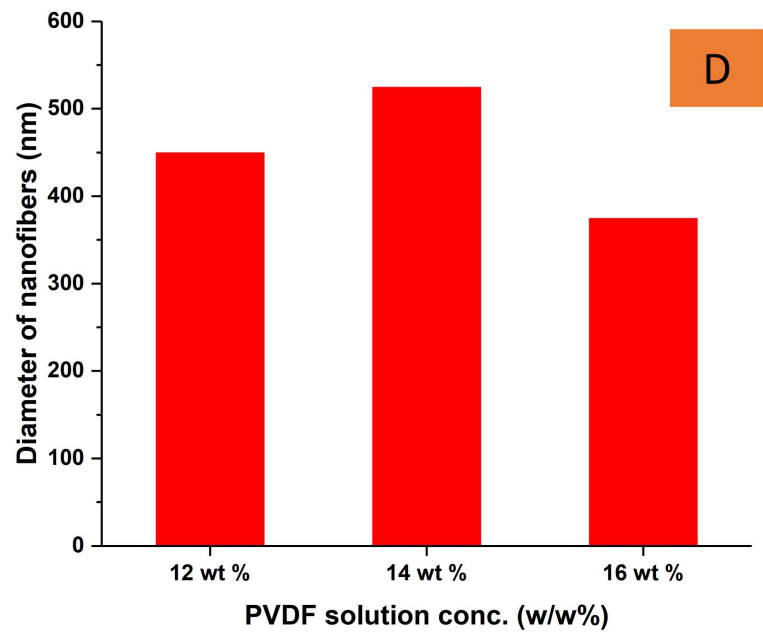

Figure 2: SEM images of nanofibers developed from $12 \mathrm{wt} \%(\mathrm{~A}), 14 \mathrm{wt} \%(\mathrm{~B})$, and $16 \mathrm{wt} \%(\mathrm{C})$. PVDF solution and average diameter variation of nanofibers against different solution concentrations (D). 


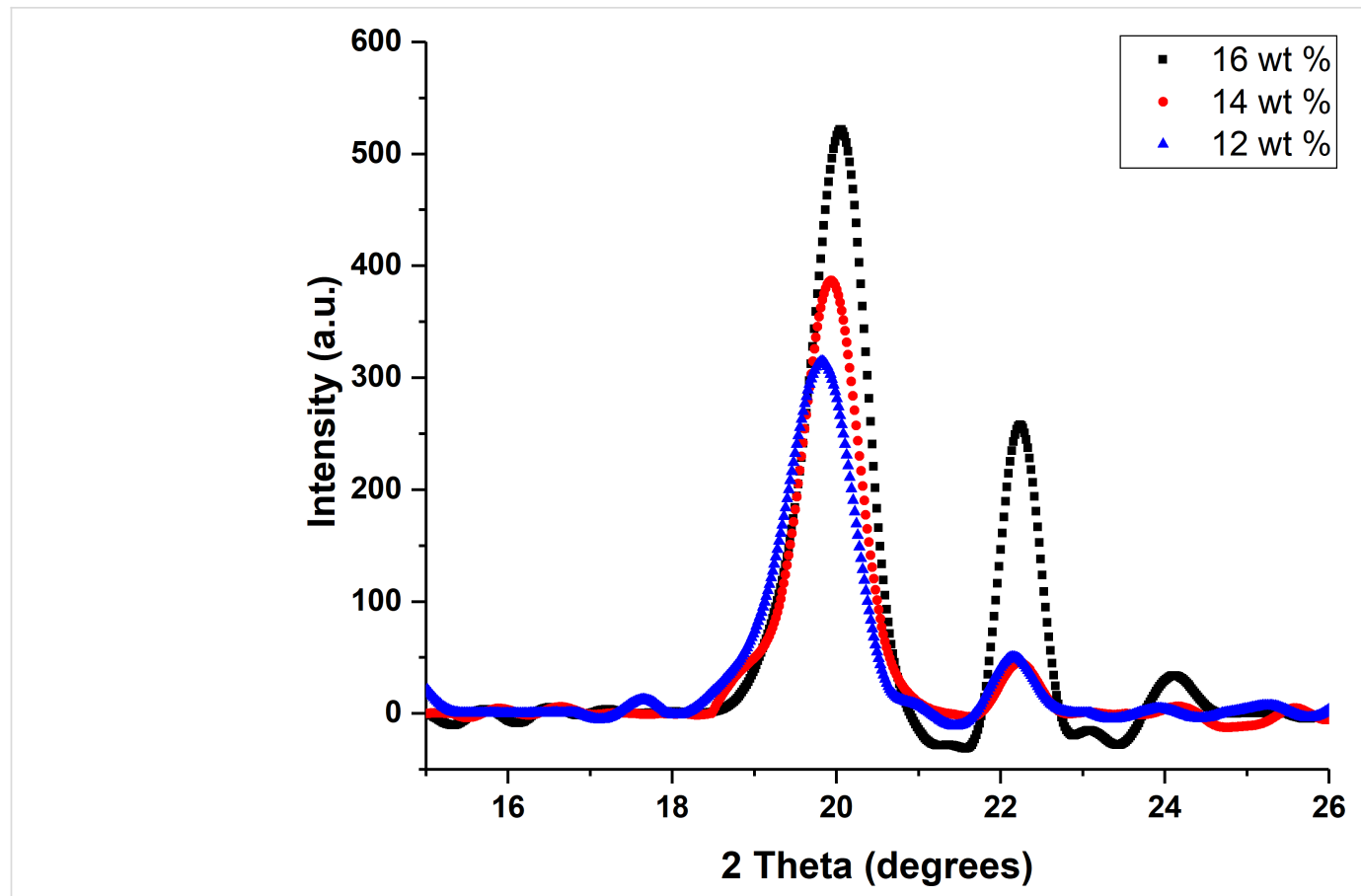

Figure 3: X-ray diffraction pattern of nanofibers at various concentrations.

amount increases in the solution it increases generation capacity [37].

\section{Digital oscilloscope analysis}

The nanofibrous mesh made from the 16 wt $\%$ solution was selected for developing the sensor (Figure 4F). These nanofibers have a smooth and defect-free morphology with highly crystalline regions, which indicate the complete evaporation of the solvent and the presence of a large amount of polymer. To check the piezoelectric output of the developed sensor, a digital oscilloscope was used and the sensor was tapped with the fingers. Silicon gloves were used to avoid any possible static charges influence [42].

The sensor was placed on a smooth surface and the wires of the sensor were connected to the probes of a digital oscilloscope. Low dynamic strain was applied onto the sensor by pressing the sensor with a finger and then lifting the finger. The process was repeated continuously to obtain the effect of low strain on the piezoelectric output. Figure 4A illustrates the result of the digital oscilloscope showing output voltage when the sensor was under to low strain. The graph showing the piezoelectric output of the PVDF nanofibrous sensor under low dynamic strain is presented in Figure 4B. It shows that under low dynamic strain the energy generation is small. To check the impact of high strain, the previous process was repeated by pressing the sensor with a high dynamic strain. Figure 4C demonstrates the result of the digital oscilloscope showing output voltage when the sensor was under high dynamic strain. The result of the piezoelectric output of PVDF nanofibrous sensor under high dynamic strain is shown in Figure 4D. Under high dynamic strain, the generated energy is higher than under low dynamic strain, which shows the direct relation between pressure and piezoelectric output. To check the impact of the frequency on the piezoelectric output, the sensor wires were attached to the probes of the digital oscilloscope and a high-frequency dynamic strain was applied onto the sensor by pressing the sensor with a finger and lifting the finger at high speed. Figure 4E shows the result of the digital oscilloscope showing the output voltage of the sensor under dynamic strain at high frequency.

To show the potential application of the developed sensor, the relation of the bending angle with the output voltage was established. For this, the sensor was integrated into a knitted fabric through stitching and a prototype representing a knee medical pad was developed (Figure 5A). The medical pad was worn onto a knee, and the knee was moved at different angles to check the output. The knee was moved from $0^{\circ}$ degrees to $120^{\circ}$ (Figure 5B). The effect of the bending angle on the output voltage was measured. When the bending angle was $45^{\circ}$, the output voltage was less than the output voltages at $90^{\circ}$ and $120^{\circ}$ because, with increasing angle, the sensor was more strained. Therefore, the bending angle and the output voltage are directly related. Figure $5 \mathrm{C}$ illustrates the voltage change with the change of the bending angle of the knee. The current density of the 
A

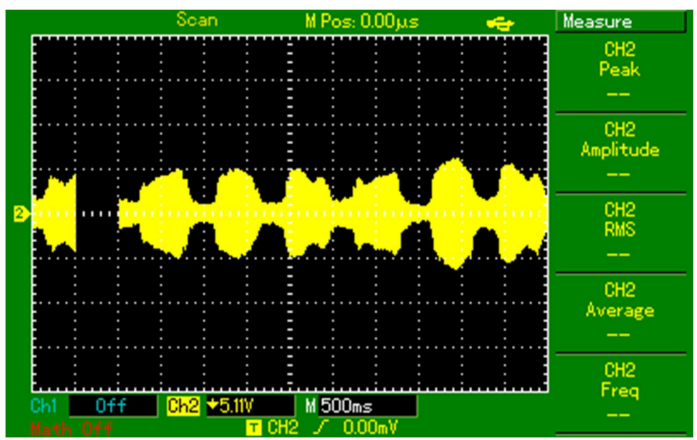

C

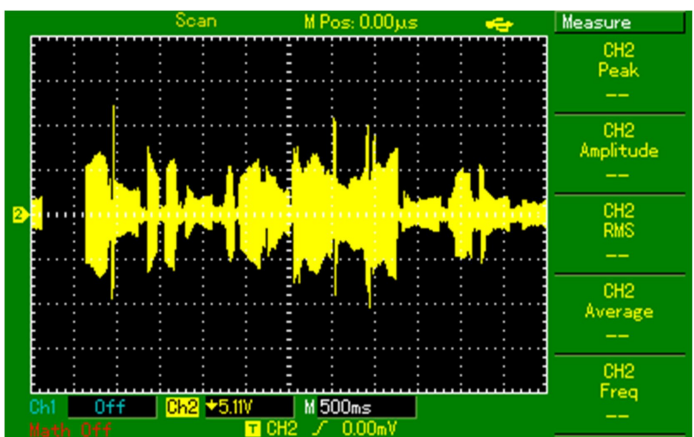

E

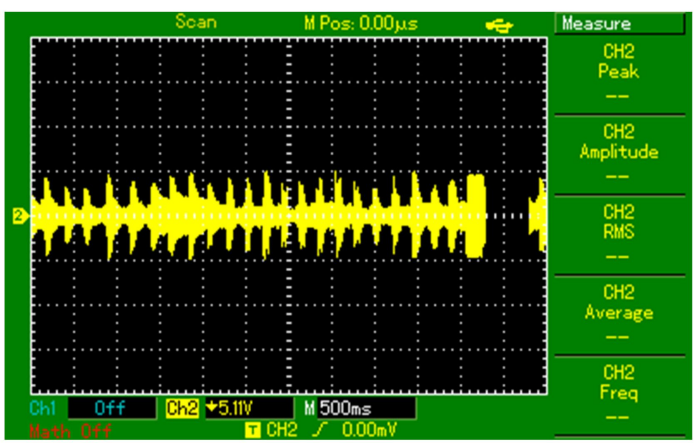

B

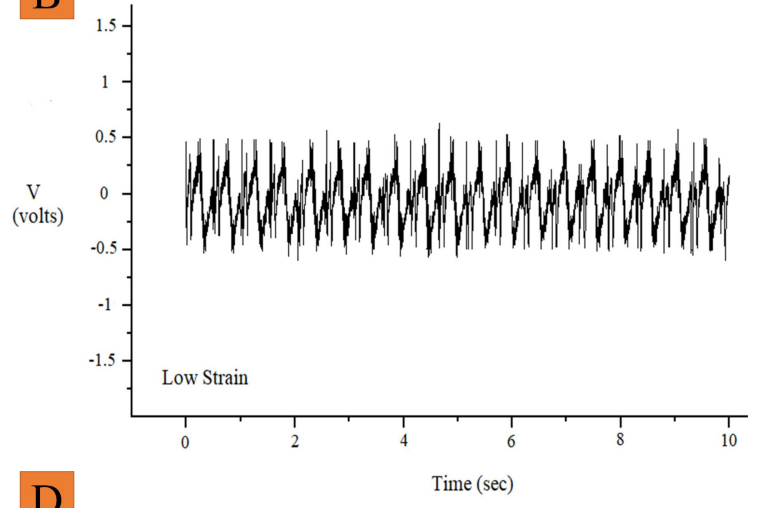

D

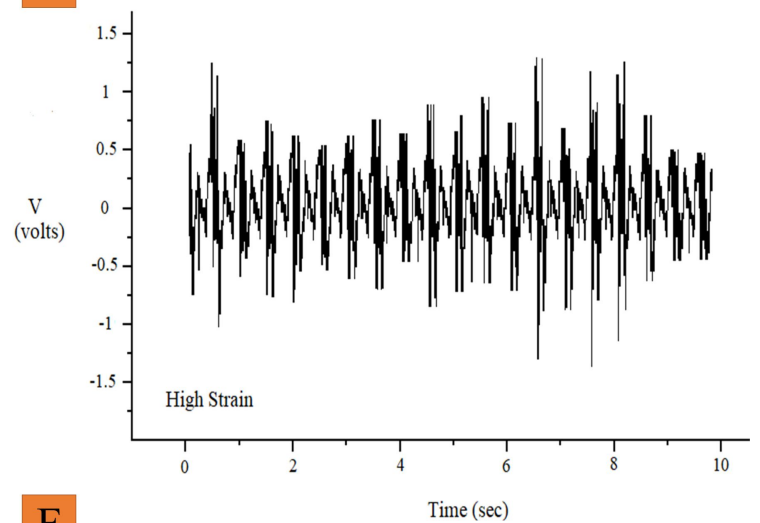

F

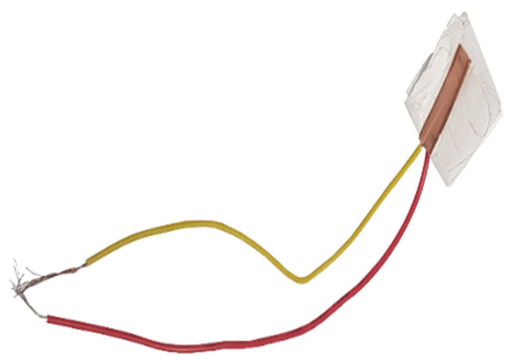

Figure 4: Digital oscilloscope graph of the sensor under low dynamic strain (A), the output voltage under low dynamic stress (B), digital oscilloscope graph of the sensor under high dynamic strain (C), the output voltage under high dynamic stress (D), digital oscilloscope graph of the sensor under low dynamic strain but with high frequency $(E)$, and a piezoelectric sensor developed from 16 wt \% solution $(F)$.

device has been calculated and compared with the current state of the art (Table 1). Clearly, the highest efficiency is shown by the device developed in the current study.

\section{Conclusion}

An experimental study on a textile-based piezoelectric sensor for human body angle monitoring has been performed. In this research, the polymeric material PVDF was used for the development of a piezoelectric nanofibrous sensor. SEM and XRD analyses were performed to determine morphology and crystalline phases of the developed nanofibers, respectively. The
SEM analysis of nanofibers confirmed smooth, defect-free, and uniform fibers produced from a solution of high concentration (16 wt \%). Additionally, the highest content of the beta phase was present in the nanofibrous mesh developed from the highly concentrated solution. Therefore, these fibers were selected for developing a piezoelectric sensor for subsequent studies. For this, the sensor was integrated into a knitted fabric through stitching to make a wearable textile-based piezoelectric sensor for human body angle monitoring. The piezoelectric output was measured by using a digital oscilloscope. The output voltage was high for high dynamic strain, which was also confirmed by 

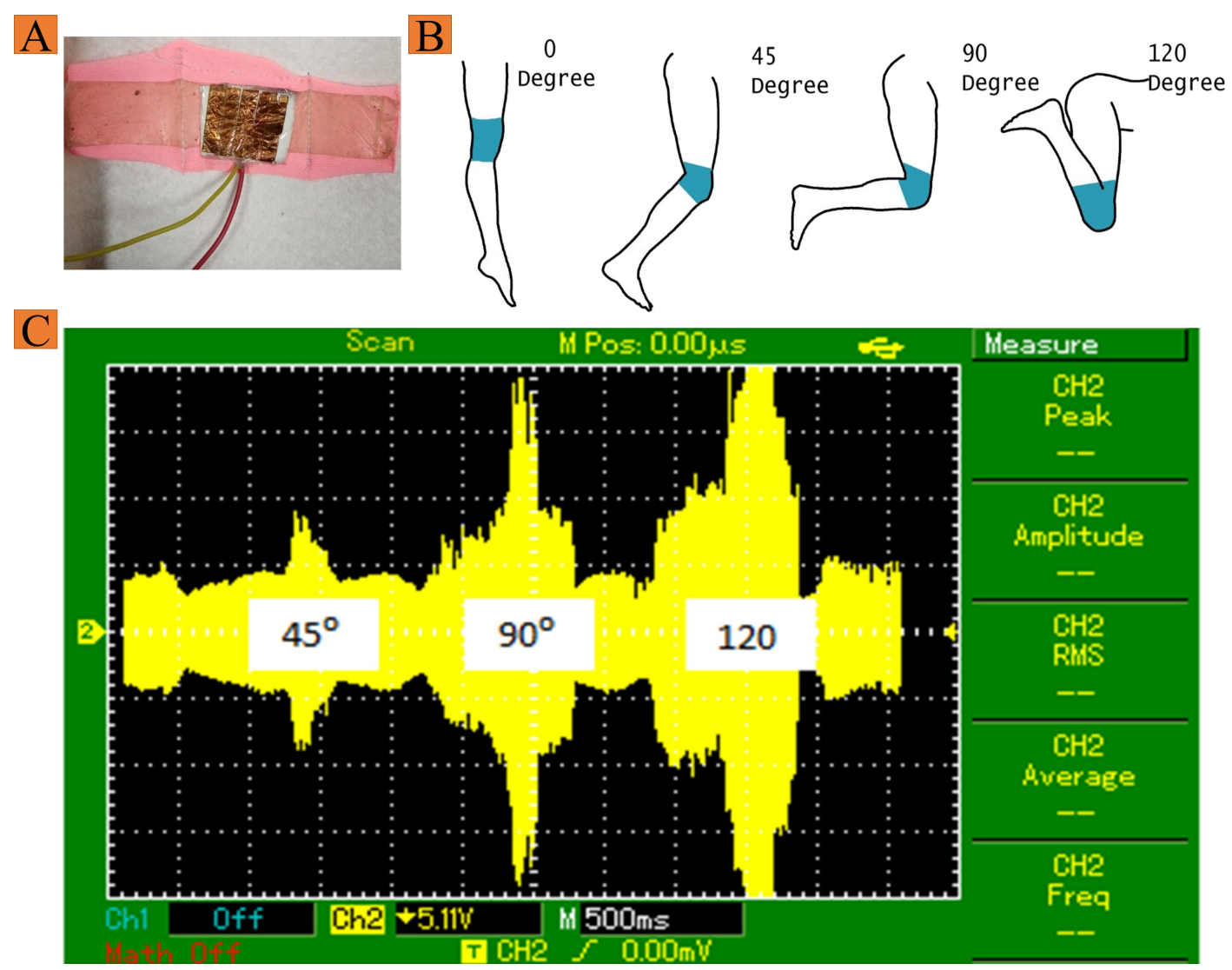

Figure 5: Integration of nanofibrous mesh into a knitted fabric for human body angle measurement (A), schematics showing the dressed knee at different bending angles (B), and digital oscilloscope graph at the corresponding angles (C).

Table 1: Comparative study of the current density.
\begin{tabular}{lllllll} 
Sr. No. & Functional material & Form & Volts $(\mathrm{V})$ & Current $(\mathrm{nA})$ & Current density $\left(\mathrm{nA} / \mathrm{cm}^{2}\right)$ & Reference \\
\hline 1 & PZT & nanotubes & 1.00 & 40.00 & - & {$[43]$} \\
2 & PZT & single crystal & 200.00 & 8000.00 & 150.00 & {$[44]$} \\
3 & PZT & composite & 10.00 & 1300.00 & 0.20 & {$[45]$} \\
4 & PVDF-TrFE & thin film & 7.00 & 58.00 & 0.56 & {$[46]$} \\
5 & PVDF & nanofiber & 2.1 & 690 & 172.50 & current study
\end{tabular}

changing the angle of the knee. The higher angle exerts more strain onto the sensor, which generates a high voltage in return. The piezoelectric output also increased when the frequency of the dynamic strain was increased. The textile-based piezoelectric sensor developed in this study has a great potential to be used as an angle measuring wearable device for the human body due to its high current density output and flexibility.

\section{Funding}

The authors sincerely acknowledge the financial support from the Higher Education Commission, Pakistan under the project of Technology Development Fund, grant number: TDF03-338.

\section{ORCID ${ }^{\circledR}$ iDs}

Muhammad Anwaar Nazeer - https://orcid.org/0000-0002-7906-8010 Muhammad Babar Ramzan - https://orcid.org/0000-0002-0401-4253

\section{References}

1. Orzan, C. M.; Florescu, M. S.; Zara, I. A.; Orzan, O. A. Ind. Text. (Bucharest, Rom.) 2020, 71, 572-575. doi:10.35530/it.071.06.202018

2. Song, Y.; Lee, S.; Choi, Y.; Han, S.; Won, H.; Sung, T.-H.; Choi, Y.; Bae, J. Fash. Text. 2021, 8, 6. doi:10.1186/s40691-020-00237-2

3. Dalsgaard, C.; Sterrett, R. Market Opportunities for Smart Textiles; Ohmatex: Denmark, 2014.

4. Baima, M.; Andrew, T. L. Fibers 2018, 6, 41. doi:10.3390/fib6020041 
5. 2011 International Conference on Control, Automation and Systems Engineering (CASE), IEEE, 2011.

6. Tognetti, A.; Bartalesi, R.; Lorussi, F.; De Rossi, D. Trans. Inst. Meas. Control (London) 2007, 29, 215-253. doi:10.1177/0142331207069487

7. Tognetti, A.; Lorussi, F.; Dalle Mura, G.; Carbonaro, N.; Pacelli, M.; Paradiso, R.; De Rossi, D. J. NeuroEng. Rehabil. 2014, 11, 56. doi:10.1186/1743-0003-11-56

8. 2006 10th IEEE International Symposium on Wearable Computers, IEEE, 2006.

9. Park, D. Y.; Joe, D. J.; Kim, D. H.; Park, H.; Han, J. H.; Jeong, C. K.; Park, H.; Park, J. G.; Joung, B.; Lee, K. J. Adv. Mater. (Weinheim, Ger.) 2017, 29, 1702308. doi:10.1002/adma.201702308

10. Lorussi, F.; Tognetti, A.; Tesconi, M.; Pastacaldi, P.; De Rossi, D. Stud. Health Technol. Inf. 2004, 108, 266-270.

11. Yoshida, M.; Akiyama, S.; Moriyama, Y.; Takeshima, Y.; Kondo, Y.; Suwa, H.; Yasumoto, K. Sens. Mater. 2021, 33, 1-16. doi:10.18494/sam.2021.2999

12. Laumann, F.; Sørensen, M. M.; Jul Lindemann, R. F.; Hansen, T. M.; Tambo, T. Energy Procedia 2017, 142, 3062-3068. doi:10.1016/j.egypro.2017.12.445

13. Madokoro, H. Piezoelectric Sensors Used for Daily Life Monitoring. Piezoelectricity - Organic and Inorganic Materials and Applications; InTech: Rijeka, Croatia, 2018. doi:10.5772/intechopen.77724

14. Park, J.-S. Adv. Nat. Sci.: Nanosci. Nanotechnol. 2011, 1, 043002. doi:10.1088/2043-6262/1/4/043002

15. Alhasssan, Z. A.; Burezq, Y. S.; Nair, R.; Shehata, N. J. Nanomater. 2018, 8164185. doi:10.1155/2018/8164185

16. Ding, Y.; Ji, C.; Yang, J.; Xu, M.; Yang, X. Sens. Mater. 2021, 33, 541-554. doi:10.18494/sam.2021.3094

17. Wu, M.; Wang, Y.; Gao, S.; Wang, R.; Ma, C.; Tang, Z.; Bao, N.; Wu, W.; Fan, F.; Wu, W. Nano Energy 2019, 56, 693-699. doi:10.1016/j.nanoen.2018.12.003

18. Sang, M.; Wang, S.; Liu, S.; Liu, M.; Bai, L.; Jiang, W.; Xuan, S.; Gong, X. ACS Appl. Mater. Interfaces 2019, 11, 47340-47349. doi:10.1021/acsami.9b16120

19. Yang, Y.; Pan, H.; Xie, G.; Jiang, Y.; Chen, C.; Su, Y.; Wang, Y.; Tai, H. Sens. Actuators, A 2020, 301, 111789. doi:10.1016/j.sna.2019.111789

20. Rana, D. S.; Chaturvedi, D.; Quamara, J. J. Optoelectron. Adv. Mater. 2009, 11, 705-712.

21. Sahu, M.; Hajra, S.; Lee, K.; Deepti, P.; Mistewicz, K.; Kim, H. J. Crystals 2021, 11, 85. doi:10.3390/cryst11020085

22. Zhang, Q. M.; Bharti, V.; Kavarnos, G. Poly(Vinylidene Fluoride) (PVDF) and its Copolymers. In Encyclopedia of Smart Materials; Schwartz, M., Ed.; John Wiley \& Sons, Inc.: Hoboken, NJ, U.S.A., 2002. doi:10.1002/0471216275.esm063

23. Liu, Z. H.; Pan, C. T.; Lin, L. W.; Huang, J. C.; Ou, Z. Y. Smart Mater. Struct. 2014, 23, 025003. doi:10.1088/0964-1726/23/2/025003

24. Yalcinkaya, F.; Hruza, J. Nanomaterials 2018, 8, 272. doi:10.3390/nano8050272

25. Kaur, S.; Sundarrajan, S.; Rana, D.; Sridhar, R.; Gopal, R.; Matsuura, T.; Ramakrishna, S. J. Mater. Sci. 2014, 49, 6143-6159. doi:10.1007/s10853-014-8308-y

26. Nazeer, M. A.; Yilgor, E.; Yilgor, I. Polymer 2019, 168, 86-94. doi:10.1016/j.polymer.2019.02.023
27. Nazeer, M.; Yilgör, E.; Yilgör, I. Hydroxyapatite synthesis through sol-gel process and preparation of poly(lactic acid)/hydroxyapatite composites through electrospinning process. In Conference: 15th AUTEX World Textile Conference 2015, Bucharest, Romania, June 10-12, 2015; 2015.

28. Zhang, X.; Chi, C.; Chen, J.; Zhang, X.; Gong, M.; Wang, X.; Yan, J.; Shi, R.; Zhang, L.; Xue, J. Mater. Des. 2021, 206, 109732. doi:10.1016/j.matdes.2021.109732

29. Zhao, R.; Li, X.; Sun, B.; Zhang, Y.; Zhang, D.; Tang, Z.; Chen, X.; Wang, C. Int. J. Biol. Macromol. 2014, 68, 92-97. doi:10.1016/j.ijbiomac.2014.04.029

30. Kucukali Ozturk, M.; Nergis, F. B.; Candan, C. Polym. Adv. Technol. 2018, 29, 1255-1260. doi:10.1002/pat.4236

31. Miletić, A.; Pavlić, B.; Ristić, I.; Zeković, Z.; Pilić, B. Appl. Sci. 2019, 9, 2955. doi:10.3390/app9152955

32. Schoolaert, E.; Hoogenboom, R.; De Clerck, K. Adv. Funct. Mater. 2017, 27, 1702646. doi:10.1002/adfm.201702646

33. Pascariu, P.; Airinei, A.; Olaru, N.; Petrila, I.; Nica, V.; Sacarescu, L.; Tudorache, F. Sens. Actuators, B 2016, 222, 1024-1031. doi:10.1016/j.snb.2015.09.051

34. Singh, R. K.; Lye, S. W.; Miao, J. Sens. Actuators, A 2020, 303, 111841. doi:10.1016/j.sna.2020.111841

35. Zhao, Y.; Qiu, Y.; Wang, H.; Chen, Y.; Jin, S.; Chen, S. Int. J. Polym. Sci. 2016, 4672839. doi:10.1155/2016/4672839

36. Gibbs, P. T.; Asada, H. H. J. NeuroEng. Rehabil. 2005, $2,7$. doi:10.1186/1743-0003-2-7

37. Cozza, E. S.; Monticelli, O.; Marsano, E.; Cebe, P. Polym. Int. 2013, 62, 41-48. doi:10.1002/pi.4314

38. Imamura, R.; Silva, A. B.; Gregorio, R., Jr. J. Appl. Polym. Sci. 2008, 110, 3242-3246. doi:10.1002/app.28851

39. Hajra, S.; Oh, Y.; Sahu, M.; Lee, K.; Kim, H.-G.; Panigrahi, B. K.; Mistewicz, K.; Kim, H. J. Sustainable Energy Fuels 2021, 5, 6049-6058. doi:10.1039/d1se01587g

40. Esterly, D. M.; Love, B. J. J. Polym. Sci., Part B: Polym. Phys. 2004, 42, 91-97. doi:10.1002/polb.10613

41. Martins, P.; Lopes, A. C.; Lanceros-Mendez, S. Prog. Polym. Sci. 2014, 39, 683-706. doi:10.1016/j.progpolymsci.2013.07.006

42. Mistewicz, K.; Jesionek, M.; Kim, H. J.; Hajra, S.; Kozioł, M.; Chrobok, Ł.; Wang, X. Ultrason. Sonochem. 2021, 78, 105718. doi:10.1016/j.ultsonch.2021.105718

43. Jung, W.-S.; Do, Y.-H.; Kang, M.-G.; Kang, C.-Y. Curr. Appl. Phys. 2013, 13, S131-S134. doi:10.1016/j.cap.2013.01.009

44. Park, K.-I.; Son, J. H.; Hwang, G.-T.; Jeong, C. K.; Ryu, J.; Koo, M.; Choi, I.; Lee, S. H.; Byun, M.; Wang, Z. L.; Lee, K. J. Adv. Mater. (Weinheim, Ger.) 2014, 26, 2514-2520. doi:10.1002/adma.201305659

45. Park, K.-I.; Jeong, C. K.; Ryu, J.; Hwang, G.-T.; Lee, K. J. Adv. Energy Mater. 2013, 3, 1539-1544. doi:10.1002/aenm.201300458 46. Pi, Z.; Zhang, J.; Wen, C.; Zhang, Z.-b.; Wu, D. Nano Energy 2014, 7, 33-41. doi:10.1016/j.nanoen.2014.04.016 


\section{License and Terms}

This is an open access article licensed under the terms of the Beilstein-Institut Open Access License Agreement (https://www.beilstein-journals.org/bjnano/terms), which is identical to the Creative Commons Attribution 4.0 International License

(https://creativecommons.org/licenses/by/4.0). The reuse of material under this license requires that the author(s), source and license are credited. Third-party material in this article could be subject to other licenses (typically indicated in the credit line), and in this case, users are required to obtain permission from the license holder to reuse the material.

The definitive version of this article is the electronic one which can be found at:

https://doi.org/10.3762/bjnano.13.14 